\title{
DE NÚMEROS A NÚMEROS: VISUALIZACIÓN DEL SONIDO POR MÉTODOS RELACIONALES DE MUESTREO EN DIRECTO
}

\author{
Carlos García Miragall \\ Universitat Politècnica de València, Dpto. Sistemas Informáticos y Computación / Laboratorio de \\ Luz
}

\section{Francisco Sanmatín Piquer}

Universitat Politècnica de València, Dpto. Pintura / Laboratorio de Luz

\section{Resumen}

Desarrollo de un método de visualización de sonido basado en las muestras numéricas obtenidas como resultado de su digitalización en tiempo real, siendo adecuado para eventos audiovisuales en directo dentro de la tradición de Música Visual. Teniendo en cuenta que: un sonido digitalizado no es más que un conjunto de números ordenados en el tiempo y una imagen no es más que un conjunto de pixeles ordenados en el espacio; el método que proponemos toma los valores numéricos de las muestras de sonido y los ubica espacialmente generando imágenes en movimiento. En función del método usado para la colocación espacial de las muestras, el número muestras de sonido y el número de fuentes sonoras, obtenemos diferentes familias de algoritmos de visualización con características estéticas propias. Este trabajo presenta las bases necesarias para abordar la visualización del sonido basada en muestras y presenta casos de estudio realizados con una aplicación desarrollada en el lenguaje de programación Java.

\section{Palabras-clave: AUDIOVISUALIZACIÓN; MÚSICA VISUAL; VISUALIZACIÓN DE DATOS; TIEMPO REAL; SONIDO EXPERIMENTAL}

\section{NUMBERS TO NUMBERS: AUDIOVISUALIZATION FOR RELATIONAL LIVE SAMPLING METHODS}

\section{Abstract}

Development of a sound visualization method based on digital samples, these samples were obtained from the real-time scanning. The method is suitable for audiovisual live events within the tradition of Visual Music. If we consider that: a digitized sound is just a set of numbers arranged in time, and an image it is no more than a set of pixels ordained in space. The proposed method takes the numerical values of the sound samples and spatially located they, generating a moving image. Depending on the method used for the spatial positioning of the samples, the number of sound samples used, and the number of sound sources, we get different visualization algorithms families with own aesthetic characteristics. This work establishes the necessary measures to address the sound visualization based on samples, and presents case studies performed with a sofware developed in Java programming language.

\section{Keywords: AUDIOVISUALIZATION; VISUAL MUSIC; DATA VISUALIZATION; REAL TIME; EXPERIMENTAL SOUND}

\footnotetext{
García Miragal1,Carlos \& Francisco Sanmatín Piquer. 2016. "De números a números: Visualización del sonido por métodos relacionales de muestreo en directo". AusArt 4(1): pp-pp. 105-117 DOI: 10.1387 /ausart.16686
}

\section{AUSART}




\section{INTRODUCCIÓN}

Cuando el sonido se estructura con una finalidad artística, como en la música, además de las propiedades físicas o psicoacústicas percibimos cualidades estéticas y conceptuales. Una interpretación visual de esos datos debe recoger también rasgos de esas cualidades físicas, estéticas y conceptuales, así como aportar nuevas ideas obtenidas de su fusión.

Respecto a las cualidades estéticas y conceptuales, la relación entre imagen y sonido ha sido considerada históricamente no como un movimiento independiente sino siempre dentro del contexto cultural y tecnológico de cada época. El análisis estético de esas relaciones se focaliza en lo que se ha venido a denominar Música Visual, que fundamenta su naturaleza en la noción de sinestesia (Brougher 2005).

Según los medios tecnológicos utilizados para la generación de imágenes, podemos diferenciar dos etapas que a finales del siglo XX convergen en los sistemas digitales. Por un lado la tradición de los instrumentos visuales, que se basa en realizar extensiones o modificaciones de instrumentos musicales con sistemas de proyección, capaces de establecer relaciones directas entre sonido e imagen -mientras se toca la música, el instrumento va generando las imágenes. Y por otro lado la tradición que deviene del uso del sonido en el cine y el video, estas tecnologías, con sus peculiaridades, permiten almacenar sonido e imagen sincronizada y procesar sus elementos de forma independiente para su posterior reunión.

Los sistemas digitales producen la convergencia a un único dispositivo, capaz de diseñar instrumentos de color, de fusionar cine/video en un único medio, de generar imagen sintética y sobre todo capaz de traducir imagen y sonido en un mismo lenguaje, el lenguaje de los números. En la actualidad, el desarrollo de la cultura digital ha incrementado las posibilidades creativas de conexión entre sonido e imagen en sus dos direcciones: tanto desde el campo del sonido hacia la visualización, como desde el campo de las artes visuales hacia el arte sonoro, siendo el lenguaje de programación su nexo común, en la mayoría de los casos.

Conscientes de este legado, el objetivo de nuestro trabajo es revisar las relaciones de comunicación entre imagen y sonido, desde sus elementos digitales básicos, a través del lenguaje informático y con una visión artística. 


\section{CONTEXTUALIZACIÓN REFERENCIAL}

\section{INSTRUMENTOS VISUALES}

Desde el siglo XVIII, científicos, artistas visuales y músicos han experimentado con instrumentos que establecían correspondencias entre las propiedades del sonido y la imagen. El primer instrumento músico-visual se le atribuye al matemático francés Louis Bertrand Castel (Peacok 1988), que en 1730 construyó el Clavicornio Ocular. Básicamente era un clavicornio modificado y cuando se pulsaba una tecla se corría una cortina desvelando así una ventana de cristal coloread o, a través de la cual pasaba un haz de luz.

En 1893, Alexander Wallace Rimington patenta el órgano de color (Rimington 1912). En 1916, el pintor futurista ucraniano Vladimir Baranoff construye el Piano Optofónico, un piano eléctrico que generaba efectos ópticos que controlaban la intensidad de la luz. El músico y pintor danés Thomas Wilfred construyó en 1919 el Clavilux, inspirado en los órganos de color (Levin 2000).

La experimentación con instrumentos visuales-musicales se ha desarrollado hasta nuestros días, en la mayoría de los casos el piano se ha sustituido por interfaces basadas en sensores y los mecanismos físicos de generación de imágenes por sistemas informáticos. Actualmente muchas de las visualizaciones se basan en el protocolo de comunicación MIDI ${ }^{1}$ entre instrumentos (Malinowski 2015; Smith 1997; Sapp 2001).

\section{El SONIDO EN EL CINE Y EL VIDEO}

Con la llegada del cine y las nuevas concepciones estéticas que impulsan las vanguardias, se abren nuevas perspectivas en las relaciones entre la música y las artes visuales. El movimiento de Abstracción, tanto en su vertiente plástica como cinematográfica, formaliza parte de su estética en los principios de composición musical (Kandinski 1996). El cine experimental en su vertiente abstracta investiga también los sincronismos entre la música y las formas geométricas, como en las obras Rhythmus 21 (1921) de Hans Richter y Symphonie diagonale (1924) de Viking Eggeling. Junto con los futuristas en los primeros años del siglo XX, artistas como el alemán Hans Stoltenberg y el finlandés Leopoldo Survage pintan directamente sobre el celuloide En los años 50, el neozelandés Len Lye utilizó técnicas de animación experimental en su obra Free Radicals (1958) rasgando el celuloide para generar líneas de luz diná- 
micas. Norman McLaren es otro artista clave de la manipulación directa de la imagen y el sonido sobre el celuloide como en su obra Loopsn (1940). En los años 70, el español Javier Aguirre construye la estructura de su película Espectro siete (1970), a partir de una partitura musical que traduce a color basándose el efecto Döppler².

Tras la Segunda Guerra Mundial, el desarrollo tecno-científico de dispositivos de análisis y visualización de sonido, como el osciloscopio y el espectrograma (Potter 1947) influyó en artistas, como la cineasta experimental estadounidense Mary Ellen Bute (Moritz 1996).

En los años sesenta y como reacción a los mass media, surge el videoarte y la videoinstalación que retoman la tradición del cine experimental con medios electrónicos. La inmediatez de resultados proporciona el entorno adecuado para la investigación de nuevas formas de presentar la imagen y el sonido. Artistas como Nan June Paik y los Vasulka, entre otros muchos, experimentaron con sintetizadores de video analógicos para generar imagen y sonido (Rekalde 1995; Baigorri 2004; Bonet [1980] 2010).

Estos dispositivos subrayaron la relación interdisciplinar arte-tecnología, por ejemplo, el investigador y artista Dan Sandin en 1970 hizo el video-sintetizador Image Processor, que podía manipular la señal de video en tiempo real. En 1968, el artista Stephen Beck construyó el primer visualizador electrónico, Direct Video Zero, que, a partir de sonido generado por un sintetizador, producía imagen sintética. En 1976 el diseñador Robert Brown fabricó el primer visualizador electrónico comercial, el Atari Video Music.

Hacia finales de los setenta y herederos de las estéticas del cine experimental y el videoarte, surge de la cultura popular el género del Videoclip Musical, como producto comercial orientado a la promoción de grupos musicales (Sánchez \& García 2009). Un aspecto interesante que aporta este género en el campo de la visualización es que las imágenes siempre se crean a partir del sonido.

\section{Medios digitales}

La expansión de la tecnología digital abre un nuevo marco para reformular la herencia analógica y plantear nuevos retos en el campo de la visualización. En 1985 la empresa Infinite Software lanza al mercado Sound to Light Generator para el ordenador ZX Spectrum, que tiene como referencia directa el Atari 
Video Music. A finales del siglo XX se produce el auge de este tipo de herramientas cuyos modelos de visualización se incorporaban como plugins en los reproductores de audio. El popular G-Force de Andy O'Meara, fue diseñado el reproductor iTunes en el año 2000. En la actualidad existe un gran número de programas de visualización con estas características.

Junto a estas iniciativas comerciales, la tecnología digital ha proporcionado un nuevo marco creativo, con la aparición de lenguajes de programación orientados al tratamiento de sonido e imagen como Pure Data, Max/Msp, OpenMusic - GAmuza, y la incorporación de librerías para tratamiento de sonido e imagen en lenguajes de programación generalistas. Una buena muestra de las posibilidades creativas en este nuevo contexto es la recopilación de trabajos que se presentan en Reline (2002) y Optofonica (2009).

A estas posibilidades se incorpora también la interactividad, desde finales de los 80 hasta nuestros días encontramos gran cantidad de propuestas de artistas como: Golan Levi, Zachary Lieberman, Robert Henke, Alva Noto, Ryoji Ikeda, Karl Kliem, Kalus Obermaier, Craig Allan, Robert Hodgin, Robin Fox, Laboratorio de Luz, Colectivo PDP11, Markus Heckman, Daniel Palacios o Fredik Olofsson, entre otros.

Antes de finalizar este repaso histórico, que en aras de presentar un resumen compacto y breve ha dejado fuera muchos autores y propuestas, queremos recoger otro factor relacionado con la visualización del sonido a través de su vibración sobre cuerpos sólidos. Son trabajos artísticos basados en la cimática, como la instalación wav (2004) de Mikel Arce. Y nos gustaría comentar también otros trabajos cuyo planteamiento es obtener sonidos a partir de imágenes, campo que se le suele denominar sonificación de la imagen (Kaper 1999).

\section{DE NÚMEROS A NÚMEROS}

En este apartado presentamos las ideas principales del método de visualización de sonido que proponemos. Inicialmente presentaremos el método a través de un ejemplo sencillo. Posteriormente realizaremos una definición más formal del método y presentaremos diferentes estrategias para abordar la ubi- 
cación espacial de las muestras de sonido que conducirán a los diferentes algoritmos de visualización.

En un sistema digital cuando capturamos sonido o imagen en movimiento éste traduce o aproxima dicha información a un conjunto de números, denominados para el sonido muestras de sonido, y para las imágenes pixeles. Estos dos tipos de medios son dependientes del tiempo y los números representan intensidad de sonido e intensidad de luz o color respectivamente.

Desde un punto de vista fisiológico para percibir sonido debe producirse una vibración exterior, por ejemplo la generada al tocar las cuerdas de una guitarra, esta vibración o energía se propaga a través del aire hasta llegar a nuestro oído que la transforma en impulsos nerviosos que finalmente interpreta el cerebro. Resulta interesante resaltar que mediante un proceso parecido al del sonido, a través de los ojos obtenemos imágenes de nuestro entorno que se convierten en impulsos nerviosos que el cerebro interpreta. Con lo que de alguna forma también usamos un lenguaje interno común para el sonido y la imagen.

El sonido es un medio del tiempo y por consiguiente del cambio, percibir el sonido es percibir cambios, en un instante determinado de tiempo el sonido no tiene entidad. Por el contrario, la dependencia de la imagen con el tiempo no es tan estrecha como con el sonido, y en un instante de tiempo una imagen representa un cuadro, una fotografía. Un instante visual es mucho más complejo que un instante sonoro. Desde un punto de vista numérico, tenemos que una muestra de sonido es un número y un fotograma de imagen en movimiento está formado por un conjunto de pixeles, donde cada pixel se representa por números. Cada pixel nos da la idea de intensidad o fuerza del color, cuyo significado es similar al de intensidad sonora. En cierta forma esta es la propiedad que vamos a usar para conectar un medio con el otro.

Lo que proponemos es generar una imagen digital usando exclusivamente la representación digital de sonido. El esquema se basa en que la representación digital interna de un sonido y de una imagen o conjunto de imágenes es en ambos casos un conjunto de números que representan intensidad sonora en el caso del sonido e intensidad lumínica en el caso de la imagen. De esta forma establecemos una relación directa entre ambos medios, a través del concepto de intensidad. Como es lógico para desarrollar este método hay una serie de parámetros adicionales que tendremos que ajustar, para que ambos medios: el sonido y su correspondiente imagen sean concordantes. 


\section{Ideas Principales}

Vamos a presentar las principales características que presenta este método a través de un ejemplo muy sencillo de forma que se vea cómo podemos visualizar los números de las muestras del sonido.

Imaginemos que tenemos conectada a la tarjeta de sonido de un sistema informático una fuente sonora, por ejemplo un teclado que emite un sonido muy simple, una onda sinusoidal. Las tarjetas de sonido traducen variaciones eléctricas en variaciones numéricas, de forma que tras un periodo de tiempo tendremos un conjunto de muestras de sonido, números. Estos números se almacenan en un vector o almacén de datos que denominamos buffer. Al cabo del tiempo volverá a llegar otro conjunto de muestras y este proceso se repetirá continuamente, obteniendo un conjunto de buffer a lo largo del tiempo:

$$
\text { ... buffer }{ }_{t-1,} \text { buffer } r^{\prime} \text { buffer }{ }_{t+1} \ldots
$$

A partir de cada buffer vamos a construir una imagen, teniendo en cuenta las siguientes condiciones:

- El número de muestras de sonido (tamaño del buffer) y el número de pixeles de cada imagen coinciden.

- El método para ubicar en la imagen las muestras de es por orden de posición en el buffer colocándolas de izquierda a derecha y de arriba abajo (idab) en la imagen.

- Las muestras de sonido se interpretan en valor absoluto

- Las muestras de sonido toman valores en el intervalo [-1..1] y los pixeles toman valores en el intervalo [0..1], donde 0 es negro, 1 es blanco y cualquier valor intermedio es un nivel de gris.

En base a estas consideraciones, y dado un buffer de 20 muestras, que representa parte de un patrón sinusoidal:

$$
\text { buffer }=\left(\begin{array}{c}
0,0.2,0.4,0.6,0.8,1,0.8,0.6,0.4,0.2,0,-0.2,-0.4, \\
-0.6,-0.8,-1,-0.8,-0.6,-0.4,-0.2,0
\end{array}\right)
$$

Obtenemos una imagen de $5 \times 4$, con los siguientes valores:

$$
\text { imagen }=\left(\begin{array}{lllll}
0 & 0.2 & 0.4 & 0.6 & 0.8 \\
1 & 0.8 & 0.6 & 0.4 & 0.2 \\
0 & 0.2 & 0.4 & 0.6 & 0.8 \\
1 & 0.8 & 0.6 & 0.4 & 0.2
\end{array}\right)
$$


Que tendrá el aspecto visual de la figura 3.1.

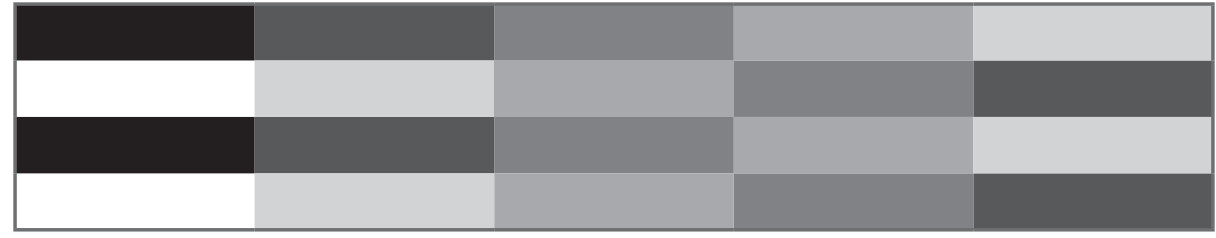

Fig 1. Imagen generada a partir de un sonido sinusoidal.

Mediante este modelo simplificado se puede apreciar como era de esperar algunas de las relaciones directas que se producen entre la imagen y el sonido. Puesto que se trata de un fragmento de sonido periódico simple, este mantiene un patrón repetitivo que se aprecia en la imagen, a través de simetrías. Estas simetrías aparecerán siempre y cuando el método de ubicación espacial de las muestras tenga en cuenta de alguna forma la posición de las muestras en el buffer. En el ejemplo hemos usado el método de izquierda a derecha y de arriba abajo, pero si usamos métodos similares las simetrías también aparecerán por ejemplo de derecha izquierda de arriba abajo, de abajo a arriba y de izquierda a derecha, y otros. En un escenario real tendremos un sistema mucho más complejo, donde el buffer varía a lo largo del tiempo y no solo tenemos un buffer sino un conjunto de buffers, uno por cada una de las líneas de entrada.

\section{FORMALIZACIÓN DE MÉTODO DE VISUALIZACIÓN}

El método que proponemos consiste en recoger a intervalos de tiempo muestras de sonido de la tarjeta de sonido, y con esos números formar una imagen. Las consideraciones fundamentales en las que se apoya el método son las siguientes: uso exclusivo de los números en valor absoluto de las muestras de sonido para construir las imágenes y correlación temporal entre las muestras de sonido y cada uno de los fotogramas de las imágenes en movimiento, de forma que para construir un fotograma en un instante determinado de tiempo $t$, sólo usaremos muestras de sonido obtenidas en dicho instante e instantes anteriores a $t$. Esto conlleva que la relación principal que se establece entre el sonido y la imagen es a través de la propiedad de intensidad, estableciendo la correspondencia intensidad sonora e intensidad visual.

El concepto de intensidad visual que estamos manejando, no se identifica necesariamente con el concepto de luminosidad. Dado un pixel de una ima- 
gen en un modelo de color RGB (Red Green Blue), este viene definido por los tres colores primarios según el sistema de mezcla aditiva (tres canales de color). En este modelo el valor numérico de cada canal de color representa la intensidad de ese color en la mezcla final.

Cada cierto tiempo (frecuencia de muestreo) la tarjeta de sonido obtiene una muestra (número) de cada una de las líneas de entrada, tendremos tantas como instrumentos conectados a ellas. Estas muestras se van almacenando en un buffer. Cuando el buffer está lleno (ha transcurrido un intervalo de tiempo determinado), este se pasa a las aplicaciones conectadas con la tarjeta de sonido para que lo procesen, en nuestro caso para generar una imagen. Por lo tanto internamente trabajamos a nivel de buffer, siendo su tamaño configurable.

Dado un instante de tiempo $t$, y dados tres buffers con $r+1$ muestras, siendo $r \in \mathrm{N}$, correspondientes a tres líneas de entrada:

$$
\text { buffer }{ }_{t}^{1}=\left\{S_{0}{ }^{1}, \ldots, S_{r}{ }^{1}\right\}, \text { buffer }{ }_{t}{ }^{2}=\left\{S_{0}{ }^{2}, \ldots, S_{r}{ }^{2}\right\} \text { y buffer }{ }_{t}{ }^{3}=\left\{S_{0}{ }^{3}, \ldots, S_{r}{ }^{3}\right\}
$$

Se obtiene como resultado la matriz de salida lienzo, en el instante $t$ :

$$
\text { Iienzo }_{t}=\left(\begin{array}{ccc}
p_{0,0} & \cdots & p_{0, m-1} \\
\vdots & \ddots & \vdots \\
p_{n-1,0} & \cdots & p_{n-1, m-1}
\end{array}\right)
$$

De manera que $n$ y $m$, son el número de filas y columnas respectivamente de la matriz lienzo, siendo $n \times m=r+1$ y $n, m \in \mathrm{N}$ y $p_{x, y}$ es el elemento de la matriz que ocupa la posición $(x, y)$, siendo $x \leq(n-1)$ y $y \leq(m-1)$ y cada elemento de la matriz $p_{x, y}$, está formado por tres valores uno para cada uno de los canales de color. Estos valores serán muestras de sonido tomadas de alguno de los tres buffers. Dependiendo de cómo asignemos estos valores obtendremos diferentes algoritmos de visualización. A continuación presentamos los más básicos, que pese a su simplicidad presentan de forma clara las posibilidades del método.

Con la finalidad de experimentar con el método y sus algoritmos de ubicación hemos diseñado una pequeña aplicación en el lenguaje de programación Java. En https://vimeo.com/user13711640 hemos dejado un conjunto de resultados en formato de vídeo con diferentes estrategias de ubicación de las muestras y sonidos, usando la aplicación desarrollada. 
En la primera estrategia las muestras de sonido se ubican de izquierda a derecha y de arriba abajo (idab) y cada buffer representa un canal de color.

Lo que obtemos es que para cada conjunto de muestras $s_{i}=\left(s_{i}{ }^{1}, S_{i}{ }^{2}, s_{i}{ }^{3}\right)$, donde $i \leq r, i \in \mathrm{N}$ y cada elemento de la terna $\left(s_{i}^{1}, s_{i}{ }^{2}, s_{i}{ }^{3}\right)$ que se corresponde con cada uno de los tres buffers respectivamente, su ubicación espacial será la posición $(x, y)$ de la matriz lienzo, donde:

$$
\begin{gathered}
x=\operatorname{div}(i, m) \\
y=\bmod (i, m)
\end{gathered}
$$

Finalmente la imagen resultante quedará de la siguiente forma:

$$
\operatorname{lienzo}_{t}=\left(\begin{array}{ccc}
S_{0} & \cdots & S_{m-1} \\
\vdots & \ddots & \vdots \\
S_{m^{*}(\mathrm{n}-1)} & \cdots & S_{\left(n^{*} m\right)-1}
\end{array}\right)
$$

Observando la figura 2, las simetrías debidas a la periodicidad del sonido en este algoritmo aparecen de forma horizontal. En el caso que el sonido sea más grave las líneas se presentan más gruesas. En https://vimeo.com/143260398, se pueden apreciar mediante los videos como además la sincronización que se produce entre el sonido y la imagen es máxima.
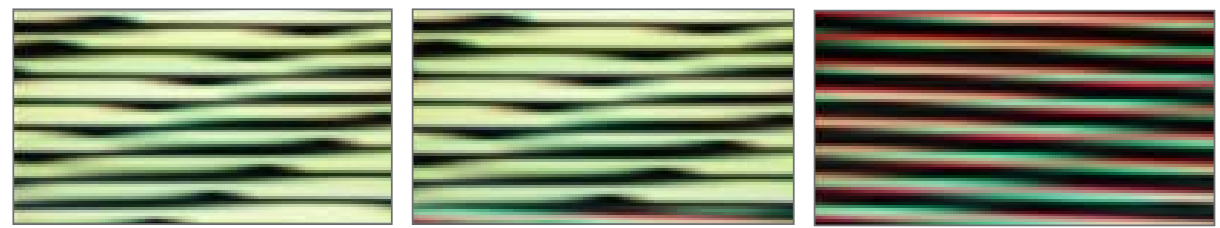

Fig. 2. Tres fotogramas obtenidos como resultado del algoritmo de ubicación idab.

En la segunda estrategia las muestras de sonido se ubican las muestras de sonido se ubican de arriba abajo y de izquierda a derecha (abid) y cada buffer representa un canal de color.

Lo que obtemos es que para cada conjunto de muestras $s_{i}=\left(s_{i}{ }_{i}, s_{i}{ }^{2}, s_{i}^{3}\right)$, donde $i \leq r, i \in \mathrm{N}$ y cada elemento de la terna $\left(s_{i}^{1}, s_{i}{ }^{2}, s_{i}{ }^{3}\right)$ que se corresponde con cada uno de los tres buffers respectivamente, su ubicación espacial será la posición $(x, y)$ de la matriz lienzo, donde:

$$
\begin{gathered}
x=\operatorname{div}(i, m) \\
y=\bmod (i, m)
\end{gathered}
$$


Finalmente la imagen resultante quedará de la siguiente forma:

$$
\text { lienzo }_{t}=\left(\begin{array}{ccc}
S_{0} & \ldots & S_{n^{*}(m-1)} \\
\vdots & \ddots & \vdots \\
S_{\mathrm{n}-1} & \cdots & S_{\left(n^{*} m\right)-1}
\end{array}\right)
$$

En la figura 3, podemos observar que las simetrías cuando tenemos sonidos periódicos se producen de forma vertical a diferencia del algoritmo anterior. Por lo demás los resultados son similares.
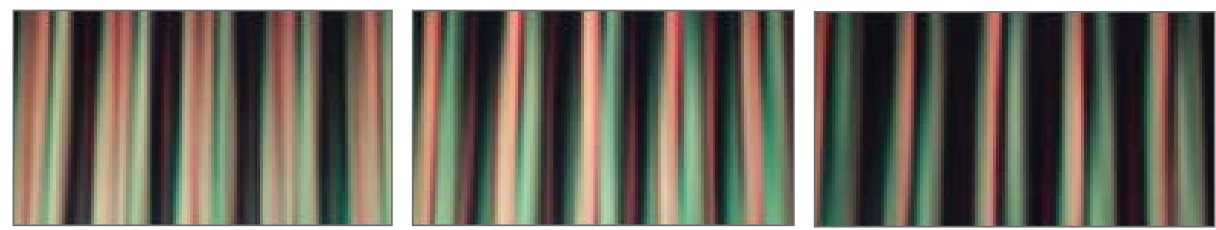

Fig. 3. Tres fotogramas obtenidos resultado del algoritmo de ubicación abid.

Cuando el sonido que tenemos es un ruido, con independencia del método de ubicación de muestras empleado, no se perciben como podemos ver en la figura 4 simetrías y lo que vemos es ruido visual.
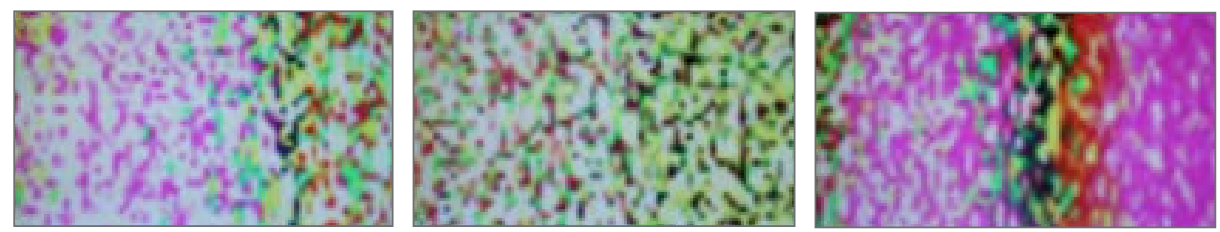

Fig. 4. Tres fotogramas generados mediante un ruido, el algoritmo de ubicación es abid.

En la figura 5, podemos ver la aplicación de un algoritmo híbrido, donde para el buffer ${ }_{1}$ y buffer $_{3}$ usamos el algoritmo de abid y para el buffer ${ }_{2}$ el de idab. Como podemos apreciar se mezclan simetrías verticales y horizontales. Es interesante resaltar que en estos casos la sensación visual es muy similar a la sonora en el sentido que se mantiene la separación de los sonidos. 


\section{CONCLUSIONES}

El método que hemos presentado, desde el punto de vista informático, se fundamenta en que el sonido y la imagen en movimiento pueden considerarse secuencias de números; tomando estos datos como base, planteamos construir imágenes en función de los números del sonido. Es importante en el método la premisa de no introducir elementos externos al sonido y ser rigurosos con respecto a la concordancia temporal. Para tal fin hemos implementado una aplicación en el lenguaje de programación Java, para experimentar con diferentes estrategias de ubicación espacial de las muestras de sonido. Las disposiciones básicas son colocar las muestras de izquierda a derecha y de arriba abajo; de arriba abajo y de izquierda a derecha. Pese a la simplicidad de los algoritmos de ubicación se pueden generar numerosas composiciones que reflejan plásticamente las relaciones entre el sonido y la imagen. Desde el punto de vista de la sincronización, las imágenes parecen bailar con el sonido $y$, al estar dividas las líneas de sonido en diferentes canales de color se pueden apreciar los diferentes instrumentos a través de las imágenes. Cuando el sonido es bastante periódico ${ }^{3}$ y se aplica una estrategia de orden de las muestras, se aprecian simetrías con características estéticas relacionadas con la frecuencia, aunque no se se haya utilizado la propiedad de frecuencia se puede la observar a través de la intensidad.

Finalmente nos gustaría comentar que el método aquí propuesto y los algoritmos de ubicación comentados suponen un importante paso en nuestra investigación, puesto que han sentado las bases de una visualización del sonido creativa basada en la propia estructura del sonido. Como futuros trabajos se plantea sobre todo profundizar más en los algoritmos de ubicación espacial, dotándolos de cierta inteligencia artificial, e incorporar el análisis de la frecuencia a través de transformadas matemáticas.

Referencias

Baigorri Ballarín, Laura. 2004. Vídeo: Primera etapa (el vídeo en el contexto social y artístico de los años 60-70). Madrid: Asociación Cultural Brumaria

Brougher, Kerry et al. 2005. Visual Music: Synaesthesia in Art and Music since 1900.

Exposición Museum of Contemporary Art (Los Angeles 13.02-22.05) y Hirshhorn Museum and Sculpture Garden (Washington D.C. 23.06-11.09). Los Angeles: The Museum of Contemporary Art 
Kandinsky, Wassily. (1911) 1996. De lo espiritual en el arte. Traducción de Genoveva Dieterich. Barcelona: Paidós

Kaper, Hans G., Elizabeth Wiebel \& Sever Tipei. 1999. "Data sonification and sound visualization". Journal Computing in Science and Engineering 1(4):48-58

Levin, Golan. 2000. "Painterly interfaces for audiovisual performance". Tesis MIT Media Laboratory

Malinowski, Stephen. 2015. "The Music Animation Machine”. Musanim.com. Acceso 14 jun. www.musanim.com

Moritz, William. 1996. "Mary Ellen Bute: Seeing sound". Animation World Network 1(2). http:/l www.awn.com/mag/issue1.2/articles1.2/moritz1.2.html

Peacock, Kenneth. 1988. "Instruments to Perform Color-Music: Two Centuries of Technological Experimentation". Leonardo 21(3): 397-406

Potter, Ralph K., George A. Kopp \& Harriet C. Green. 1947. Visible Speech. New York: Van Nostrand

Sánchez López, Juan Antonio \& Francisco García Gómez, coords. 2009. Historia, estética e iconografía del videoclip musical. Málaga: Universidad de Málaga

Rekalde Izagirre, Josu. 1995. Vídeo, un soporte temporal para el arte. Bilbao: Universidad del País Vasco/EHU

Sapp, Craig Stuart. 2001. "Harmonic visualizations of tonal music". International Computer Music Conference Proceedings vol. 2001: 423-30

Smith, Sean M. \& Glen N. Williams. 1997. "A visualization of Music". IEEE Visualization Conference 1997: 499-502. doi:10.1109/visual.1997.663931

Rimington, Alexander Wallace. 1912. Color music: The art of mobile color. London: Hutchinson \& Company

Bonet, Eugeni, et al. (1980) 2010. En torno al vídeo. Coordinación, Fito Rodríguez Bornaetxea y Natxo Rodríguez Arkaute. Leioa: Universidad del País Vasco/EHU

Notas

${ }^{1}$ MIDI son las siglas de Musical Instrument Digital Interface, se trata de un protocolo de comunicación diseñado inicialmente para controlar sintetizadores.

${ }^{2}$ El efecto Döppler es el aparente cambio de frecuencia de una onda producido por el movimiento relativo de la fuente respecto a su observador.

\footnotetext{
(Artículo recibido 10.04.16; aceptado 19.05.16)
} 